\title{
Investigation of Three-Dimensional Evolution of East Asian Dust Storm by Modeling and Remote Sensing Measurements
}

\author{
Jiawei Li and Zhiwei Han \\ Key Laboratory of Regional Climate-Environment for Temperate East Asia (RCE-TEA), Institute of Atmospheric Physics (IAP), \\ Chinese Academy of Sciences (CAS), Beijing 100029, China
}

Correspondence should be addressed to Zhiwei Han; hzw@mail.iap.ac.cn

Received 3 June 2014; Accepted 16 September 2014

Academic Editor: Hesham El-Askary

Copyright (c) $2015 \mathrm{~J}$. Li and Z. Han. This is an open access article distributed under the Creative Commons Attribution License, which permits unrestricted use, distribution, and reproduction in any medium, provided the original work is properly cited.

The three-dimensional evolution of an East Asian dust storm during 23-26 April 2009 was investigated by utilizing a regional air quality model system (RAQMS) and satellite measurements. This severe dust storm hit Mt. Tai in east China with daily mean $\mathrm{PM}_{10}$ concentration reaching $1400 \mu \mathrm{g} / \mathrm{m}^{3}$ and the model captured the $\mathrm{PM}_{10}$ variation reasonably well. Modeled spatial distributions of AOD and vertical profiles of aerosol extinction coefficient during the dust storm were compared with MODIS and CALIPSO data, demonstrating that RAQMS was able to reproduce the 3D structure and the evolution of the dust storm reasonably well. During early days of the dust storm, daily mean dust-induced AOD exceeded 2.0 over dust source regions (the Gobi desert and the Taklamakan desert) and was in a range of 1.2-1.8 over the North China Plain, accounting for about $98 \%$ and up to $90 \%$ of total AOD over corresponding areas, respectively. The top of the dust storm reached about $8 \mathrm{~km}$ over east China, with high dust concentration locating at around $40^{\circ} \mathrm{N}$. Dust aerosol below $2 \mathrm{~km}$ was transported southeastward off the Gobi desert while dust above $2 \mathrm{~km}$ was transported out of China along $40^{\circ}-45^{\circ} \mathrm{N}$.

\section{Introduction}

Dust aerosol is one of the most important aerosol components because it is a major contributor to global atmospheric aerosol loading and optical thickness. Recent estimates of its global source strength range from 1000 to $5000 \mathrm{Mt} /$ year with highly varied spatial-temporal distribution [1]. When surface wind speeds are strong enough, dust particles are injected into the atmosphere from source regions and then subjected to long-range transport [2-6], degrading air quality and even disturbing regional climate. For example, Huang et al. found that dust aerosol can heat the air over Taklamakan desert by a maximum of $5 \mathrm{~K} /$ day in summertime [7]; Lau et al. found that dust can be a cause of East Asian monsoon anomaly [8].

East Asia is one of the major dust source regions in the world. There are two major sources, namely, the Taklamakan desert in west China and the Gobi desert across south Mongolia and north China. Dust storms are most active in springtime [3, 4]. Severe dust storms not only exert significant impacts on East Asia itself but also can reach as far as the west coast of North America [9]. Several methods have been used to understand the evolution and the impact of East Asian dust storm on atmospheric environment and climate. In situ sampling (e.g., $[4,10])$ and remote sensing by ground-based lidar (e.g., [11]) and by satellite (e.g., [9]) are primary methods in understanding sources, optical properties, compositions, and spatial distributions of dust storm. Since 2006, a new instrument, the space-based two-wavelength, polarizationsensitive backscatter lidar, the Cloud-Aerosol Lidar with Orthogonal Polarization (CALIOP) on board the CloudAerosol Lidar and Infrared Pathfinder Satellite Observations (CALIPSO) satellite began to provide continuous global measurements of aerosol vertical distribution with high spatial resolution [12]. This instrument provides a top-down view to investigate the vertical structure of aerosols including dust. Based on CALIPSO measurements, some studies have investigated vertical characteristics and spatial-temporal variation of dust storms (e.g., $[13,14])$. Numerical model is another important scientific tool in understanding dust related problems because it is able to represent and interpret the complex processes and mechanisms of dust evolution. A number of dust models have been established and applied 
to investigate dust's generation, long-range transport, climate effects, and perturbation to atmospheric chemistry in East Asia (e.g., [5, 6, 15-17]).

In this paper, we studied the three-dimensional structure and evolution of dust storm over East Asia in April 2009 by utilizing a regional air quality model system (RAQMS), mainly focusing on the dust storm period during 23-26 April. In situ observations at the summit of the Mt. Tai (locating in east China), satellite retrievals of aerosol optical depth (AOD), and space-based lidar measurements are collected and used to verify model simulations and investigate the transport process of the dust storm. Spatial distributions of dust aerosol and dust-induced AOD, as well as vertical distribution of dust extinction coefficient during the dust storm period, were further discussed.

\section{Model Description}

The regional air quality model system (RAQMS) is a three-dimensional Eulerian model constructed on a terrainfollowing spherical coordinate system. The model contains a series of key processes related to atmospheric pollutants including emission, advection, diffusion, multiphase chemistry, dry deposition, and wet scavenge $[6,17]$. The SAPRC99 (Statewide Air Pollution Research Center) mechanism proposed by Carter [18] was applied to account for gas phase chemistry. The ISORROPIA II model had been embedded into RAQMS to represent the thermodynamic equilibrium processes among inorganic aerosols [19]. A bulk yield scheme was used to deal with the formation of secondary organic aerosol (SOA) [20]. Heterogeneous reactions between dust aerosol and gases had also been considered [21]. Inorganic and carbonaceous aerosols were assumed to fit the lognormal distribution and settle in fine mode. Soil dust and sea salt aerosols were represented by a sized-segregated submodule including key processes for dust and sea salt such as generation, dry deposition, and wet scavenging, in which dust was divided into 10 size bins ranging from $0.43 \mu \mathrm{m}$ to $42 \mu \mathrm{m}$ and sea salt was divided into 8 size bins ranging from $0.43 \mu \mathrm{m}$ to $17.5 \mu \mathrm{m}$ [6]. Dry deposition of gaseous species was parameterized based on the method of Walmsley and Wesely [22] except gas phase sulfate whose dry deposition velocities was calculated by the approach of Walcek et al. [23]. Dry deposition velocities of aerosols were calculated as the inverse of total resistances plus the gravitational settling term [6]. The subgrid cloud mixing, scavenging of gas species, and aqueous chemistry were similar to those used in the second-generation regional acid deposition model [24]. Below-cloud scavenging of aerosols between cloud base and ground surface was parameterized based on an expression of scavenging rate that is a function of precipitation rate and collision efficiency of particle by hydrometeor [6]. Inorganic aerosols were treated as internally mixed, whereas black carbon, organic carbon, dust, and sea salt were treated as externally mixed with inorganic components. The kappa parameterization [25] was adopted to account for the hygroscopic growth of aerosol diameter. Aerosol optical properties such as extinction, single scattering albedo, and asymmetry

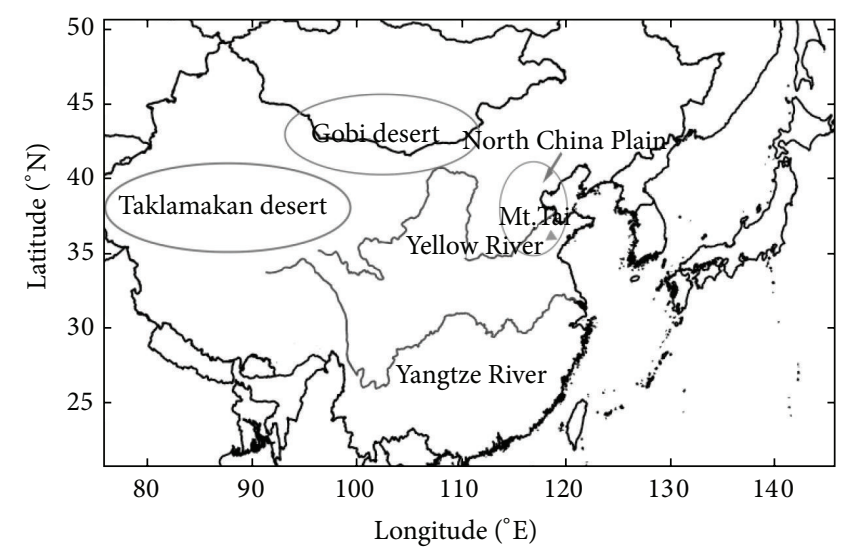

FIGURE 1: Model domain, location of Mt. Tai, and major landmarks.

factor were calculated by a Mie-theory-based method [26]. The RAQMS model had already been facilitated in a number of studies concerning regional environmental problems in East Asia such as tropospheric ozone, acid deposition, and dust storm $[6,17,27]$.

In this work the RAQMS was facilitated with a horizontal resolution of $0.5^{\circ} \times 0.5^{\circ}$. Twelve vertical layers stretch unequally from ground to about $10 \mathrm{~km}$ (the intermediate heights of each layer are about $50 \mathrm{~m}, 150 \mathrm{~m}, 300 \mathrm{~m}, 500 \mathrm{~m}$, $750 \mathrm{~m}, 1500 \mathrm{~m}, 2500 \mathrm{~m}, 3500 \mathrm{~m}, 4500 \mathrm{~m}, 6000 \mathrm{~m}, 7500 \mathrm{~m}$, and $8950 \mathrm{~m}$ ). The model domain covers most areas of East Asia including most China, the Korean Peninsula, Japan, Mongolia, and the West Pacific, ranging between $75^{\circ} \mathrm{E}$ to $145^{\circ} \mathrm{E}$ and $20^{\circ} \mathrm{N}$ to $50^{\circ} \mathrm{N}$ (Figure 1).

Monthly varied anthropogenic emission inventories for $\mathrm{CO}$ (carbon monoxide), $\mathrm{NO}_{x}$ (nitrogen oxides), $\mathrm{SO}_{2}$ (sulfur dioxide), BC (black carbon), POC (primary organic carbon), NMVOCs (non-methane volatile organic compounds), and primary particulate matters (emitted from industry, construction, exposed surface, etc.) were obtained from MEIC (Multi-resolution Emission Inventory for China) model provided by Tsinghua University (http://meicmodel.org) for China and from US NASA's (National Aeronautics and Space Administration) INTEX-B (Intercontinental Chemical Transport Experiment-Phase B) project [28] for the rest of the domain. The MEIC inventory was used to represent emission condition in 2009, and the INTEX-B inventory was based on the year 2006. Monthly biomass burning emissions were obtained from the Global Fire Emission Database version 3.1 based on the year 2009 [29].

The nonhydrostatic, fifth-generation mesoscale model (MM5) was applied to provide meteorological fields of wind, temperature, humidity, and other parameters to drive RAQMS. Four-dimensional data assimilation (FDDA) technique was used when running MM5 to enhance the simulation accuracy of key meteorological parameters. NCEP (National Centers for Environmental Prediction) reanalysis data with temporal resolution of 6 hours and spatial resolution of $1^{\circ} \times 1^{\circ}$ were used to provide initial and boundary conditions of MM5. 


\section{Observations}

Daily $\mathrm{PM}_{10}$ samples were collected in a 24-hour interval from 27 March to 26 April 2009 at the summit of a mountain site (Mt. Tai, $36.27^{\circ} \mathrm{N}, 117.10^{\circ} \mathrm{E}, 1545 \mathrm{~m}$ a.s.l., Figure 1 ) in east China. On 24 April an intensive dust storm arrived in Mt. Tai, during which $\mathrm{PM}_{10}$ sampling time was changed into 3-6 hours. Information of this observation data such as instruments and analytical method was documented in detail in Wang et al. [10].

Daily AOD data at $550 \mathrm{~nm}$ from MODIS (ModerateResolution Imaging Spectroradiometer) on board Aqua satellite was collected. Two AOD products, namely, the Level-3 MODIS "Land and Ocean" AOD product and the Level-3 "Deep Blue Land only" AOD product, were used for model validation during the dust storm period. The "Land and Ocean" product can provide retrievals on areas out of the dust source regions including ocean and east/south China, but it cannot provide sufficient retrievals over desert areas. The "Deep Blue Land only" product, however, can provide retrievals over the entire continent including desert areas theoretically, but this product does not provide any retrieval over ocean. Using these two products at the same time can obtain as much AOD information about this dust storm as possible. Both products are in the resolution of $1^{\circ} \times 1^{\circ}$. The retrieval time of MODIS on board Aqua is around 13:30 (Local Standard Time). The MODIS instrument is also on board another satellite Terra; however, during this dust storm period, data quality of retrievals from MODIS-Terra was too low to be used, so MODIS-Terra data were not used in this work.

Vertical distributions of aerosol and cloud information were measured by the space-based lidar CALIOP on board the CALIPSO satellite [12]. The CALIOP Level 2 aerosol profile products (ver. 3.01) containing aerosol profile extinction coefficient at $532 \mathrm{~nm}$ were obtained and used in this study to verify modeled aerosol extinction coefficient profiles. The horizontal resolution of the CALIOP Level 2 aerosol profile product is $5 \mathrm{~km}$ and the vertical resolution is $60 \mathrm{~m}$. The lidar signal inversion is started from around $30 \mathrm{~km}$ down to the ground surface. Atmospheric Volume Description (AVD) flag and Cloud-Aerosol Discrimination (CAD) score that were contained in the Level 2 product were used to screen out aerosol extinction coefficient profiles containing cloud signals by the method described in the user's guide webpage (http://www-calipso.larc.nasa.gov/resources/ calipso_users_guide/tools/index.php). CALIOP measurements are available both at daytime and nighttime. Considering data quality, one profile was selected per day within the model domain on days 23, 24, and 26 and two profiles were used on day 25.

\section{Model Validations}

4.1. Comparison with Ground-Level $P M_{10}$ Observation at Mt. Tai. Comparison between simulated and observed daily concentrations of $\mathrm{PM}_{10}$ and inorganic components at Mt. Tai from 27 March to 26 April 2009 are presented in Figure 2. The model reproduced the magnitude and temporal variation of $\mathrm{PM}_{10}$ concentration at this site and correctly captured the arrival of the dust storm on 23 April, the peak on 24 April, and its passing after 25 April. The observation revealed that the strength of this dust storm was so strong that daily mean $\mathrm{PM}_{10}$ concentration reached as high as $\sim 1400 \mu \mathrm{g} / \mathrm{m}^{3}$ and the maximum concentration approached $\sim 1800 \mu \mathrm{g} / \mathrm{m}^{3}$ (sampling interval of 3 hours). The model captured such characteristics, predicting daily $\mathrm{PM}_{10}$ to be $\sim 1600 \mu \mathrm{g} / \mathrm{m}^{3}$. During the observation period, mean $\mathrm{PM}_{10}$ concentrations from observation and simulation were $201 \mu \mathrm{g} / \mathrm{m}^{3}$ and $200 \mu \mathrm{g} / \mathrm{m}^{3}$, respectively, with correlation coefficient of 0.92 . For sulfate, nitrate, and ammonium, the model generally reproduced the temporal variations but tended to underpredict their daily concentrations, which could be attributed to the relatively coarse model resolution that cannot distinguish their emission gradients between urban and mountain areas. Besides, the chemical mechanism of nitrate is too complex and cannot be well treated in atmospheric chemistry models, which is also a reason resulting in the relatively poor performance for nitrate. For instance, heterogeneous reactions between gaseous precursors $\left(\mathrm{HNO}_{3}, \mathrm{~N}_{2} \mathrm{O}_{5}, \mathrm{NO}_{2}\right.$, etc.) and atmospheric aerosols (dust and other aerosol types) [21] and the impact of HONO chemical mechanism [30] are not well understood nowadays. It should be mentioned that nitrate and nitrogen oxides are also often poorly predicted in present chemical transport models [27, 31]. During the sampling period, mean observed concentrations of sulfate, nitrate, and ammonium were $16.7 \mu \mathrm{g} / \mathrm{m}^{3}, 20.1 \mu \mathrm{g} / \mathrm{m}^{3}$, and $12.0 \mu \mathrm{g} / \mathrm{m}^{3}$, respectively, while those from model simulation were $13.5 \mu \mathrm{g} / \mathrm{m}^{3}, 15.2 \mu \mathrm{g} / \mathrm{m}^{3}$, and $7.4 \mu \mathrm{g} / \mathrm{m}^{3}$. The comparison with observation at Mt. Tai showed that a severe dust storm hit east China during 23-26 April and demonstrated that RAQMS reproduced the impact of this dust storm on east China properly on both aspects of timing and strength. In the following sections, model comparisons with remote sensing measurements will be focused on the dust storm period.

4.2. Comparison with MODIS Retrieved AOD. Figure 3 shows daily AOD retrievals from MODIS on board the Aqua satellite and model results. Simulated AOD was sampled according to corresponding MODIS retrievals. From Deep Blue MODIS retrieval (Figure 3(c)), the dust storm occurred on 23 April over the Gobi desert; as a result, AOD over the Gobi desert was about 2.0-3.2. Meanwhile, large amount of dust was also generated over the Taklamakan desert, resulting in maximum AOD of approaching 4.0. The model correctly reproduced locations of high AOD centers over these deserts but with some overprediction (Figure 3(d)). Dust aerosol was nearly the only contributor to total AOD over dust source regions, with percentage contribution of up to $98 \%$ over the two deserts estimated by the model (shown in Figures 3(b) and 3(d) are fractional values).

The main body of the dust storm originated from the Gobi desert moved southeastward to the North China Plain on 24 April, exerting significant influences on this area. Both MODIS retrievals (Figures 3(a) and 3(c)) and simulations (Figures 3(b) and 3(d)) revealed the high AOD center over the North China Plain with the value in a range of 1.2 to around 


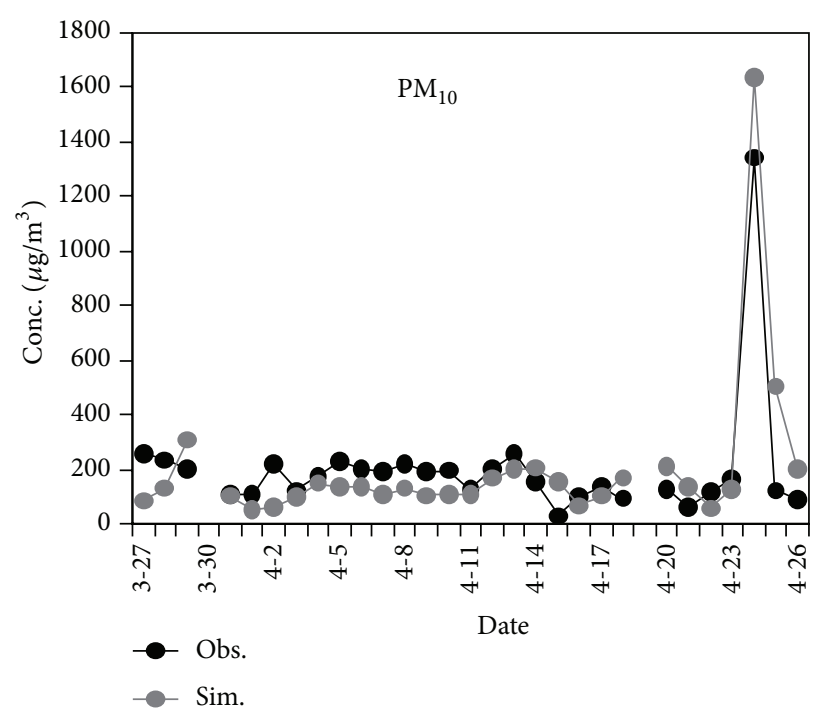

(a)



(c)

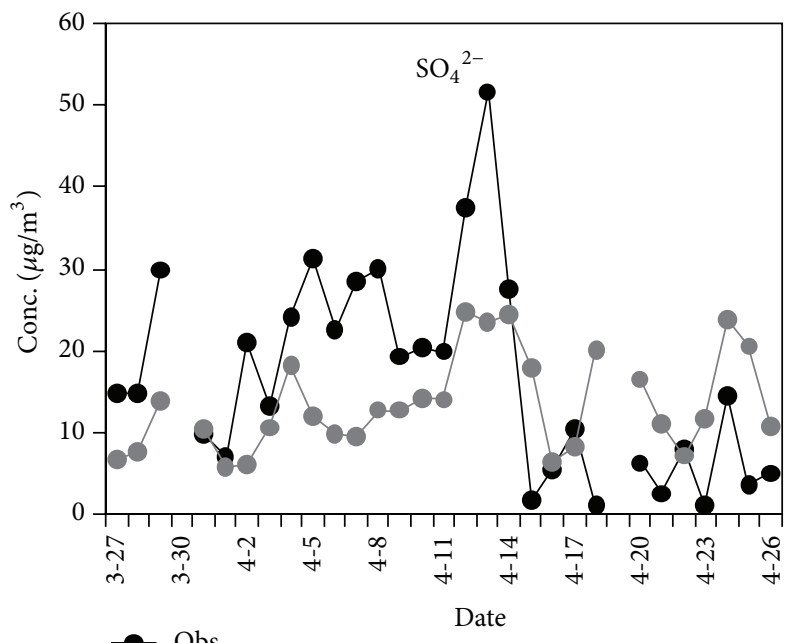

- Obs.
- Sim.

(b)

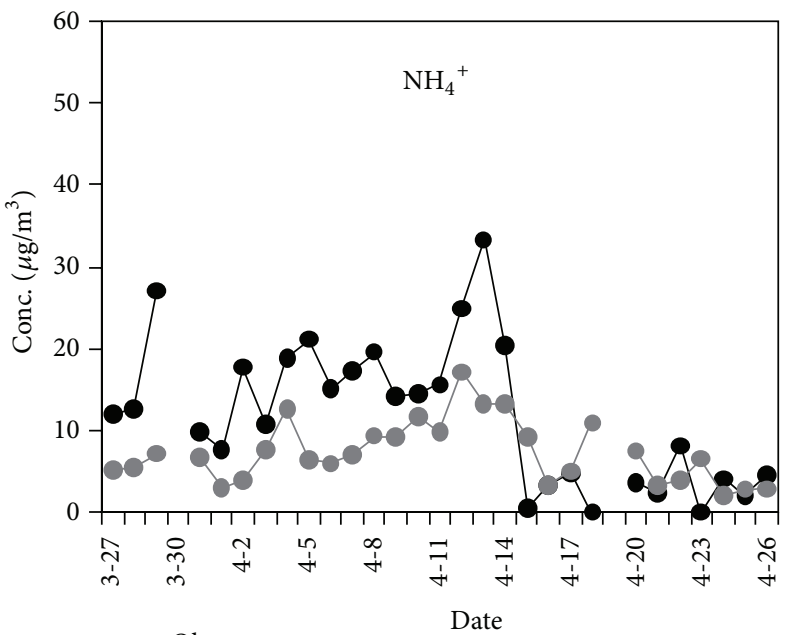

(d)

FIGURE 2: Comparisons between observed and simulated ground-level daily mean concentrations of $\mathrm{PM}_{10}$, sulfate $\left(\mathrm{SO}_{4}{ }^{2-}\right)$, nitrate $\left(\mathrm{NO}_{3}{ }^{-}\right)$, and ammonium $\left(\mathrm{NH}_{4}^{+}\right)$at Mt. Tai.

3.6; meanwhile, both retrievals and simulations showed that AOD over the Taklamakan desert was in a range of 1.0-4.0. The contribution of dust to total AOD still remained at a high level. The model estimation of the percentage contribution of dust was up to $90 \%$ over most areas of the North China Plain and $>90 \%$ over the Taklamakan desert.

The body of the dust storm moved further southward on 25 April but with weaker strength. MODIS retrieval indicated that on 25 April, high AOD appeared over south China (areas south of the middle and lower reaches of the Yangtze River) with values of about 1.2-2.0 (Figure 3(a)). The model reproduced the magnitude and the distribution pattern of AOD over these areas (Figure 3(b)). However, the model slightly underpredicted AOD over the Taklamakan desert and parts of the North China Plain (Figures 3(c) and 3(d)). On this day, the contribution of dust to total AOD became smaller over east China, the estimated percentages ranged from $40 \%$ to $60 \%$ over high AOD areas on south China. It should be noticed that there was a branch of dust over northeast China which was not depicted as clear as the main body of the dust storm in satellite figures due to the relatively smaller $A O D$ values and insufficient valid retrieval data there, and the model reproduced this branch.

This dust storm almost finished on 26 April. Both MODIS (Figure 3(a)) and RAQMS (Figure 3(b)) indicated that high AOD mainly appeared over south China, with values decreased to a range of 0.8-1.6, and dust accounted for only about $40 \%$ of total AOD over large portions of these areas. The model underpredicted AOD over the Taklamakan desert on this day (Figures 3(c) and 3(d)). 

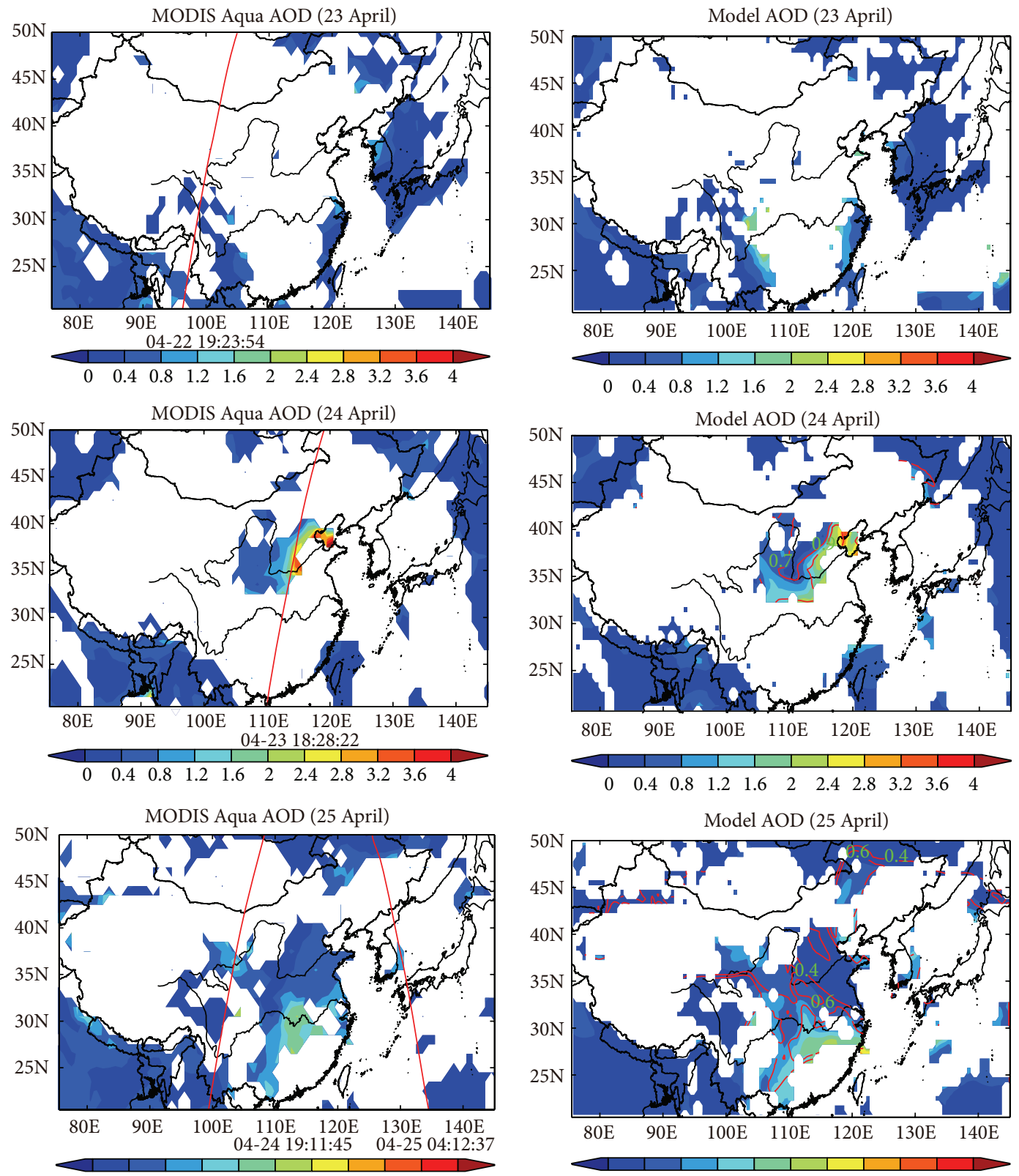

Model AOD (25 April)

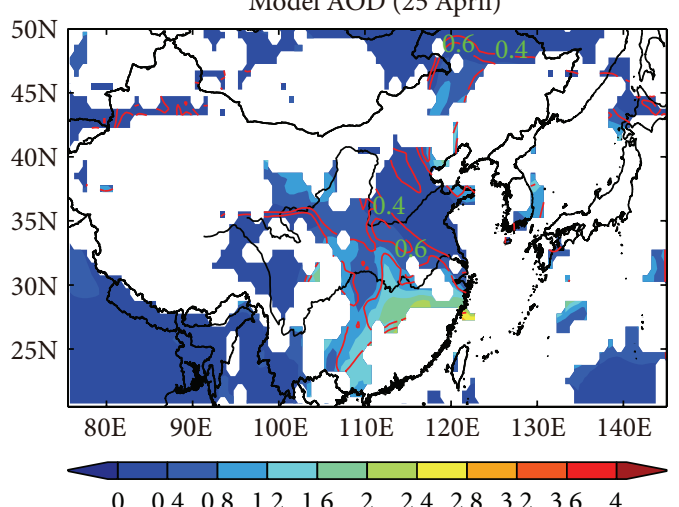

$\begin{array}{lllllllllll}0 & 0.4 & 0.8 & 1.2 & 1.6 & 2 & 2.4 & 2.8 & 3.2 & 3.6 & 4\end{array}$
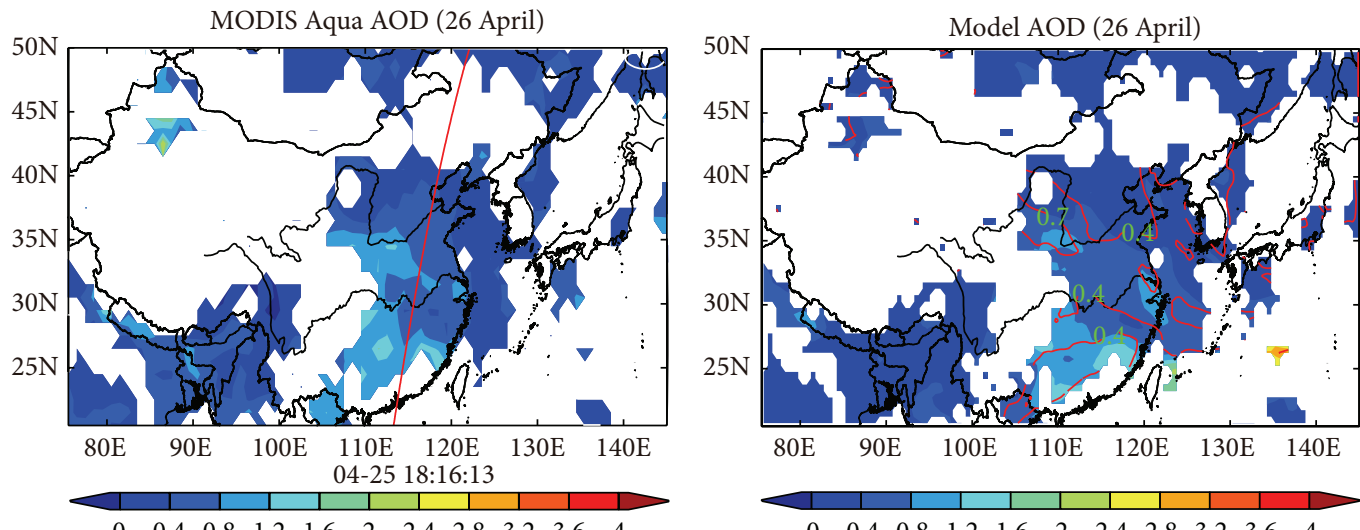

$\begin{array}{lllllllllll}0 & 0.4 & 0.8 & 1.2 & 1.6 & 2 & 2.4 & 2.8 & 3.2 & 3.6 & 4\end{array}$

(a)

(b)

Figure 3: Continued. 

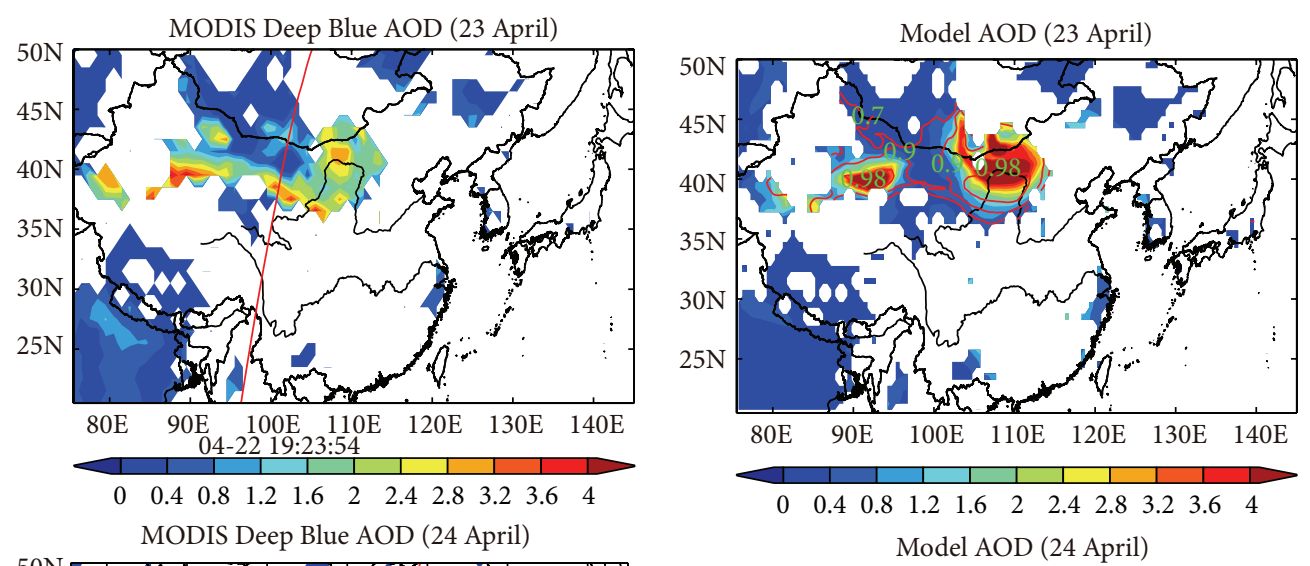

$\begin{array}{lllllllllll}0 & 0.4 & 0.8 & 1.2 & 1.6 & 2 & 2.4 & 2.8 & 3.2 & 3.6 & 4\end{array}$
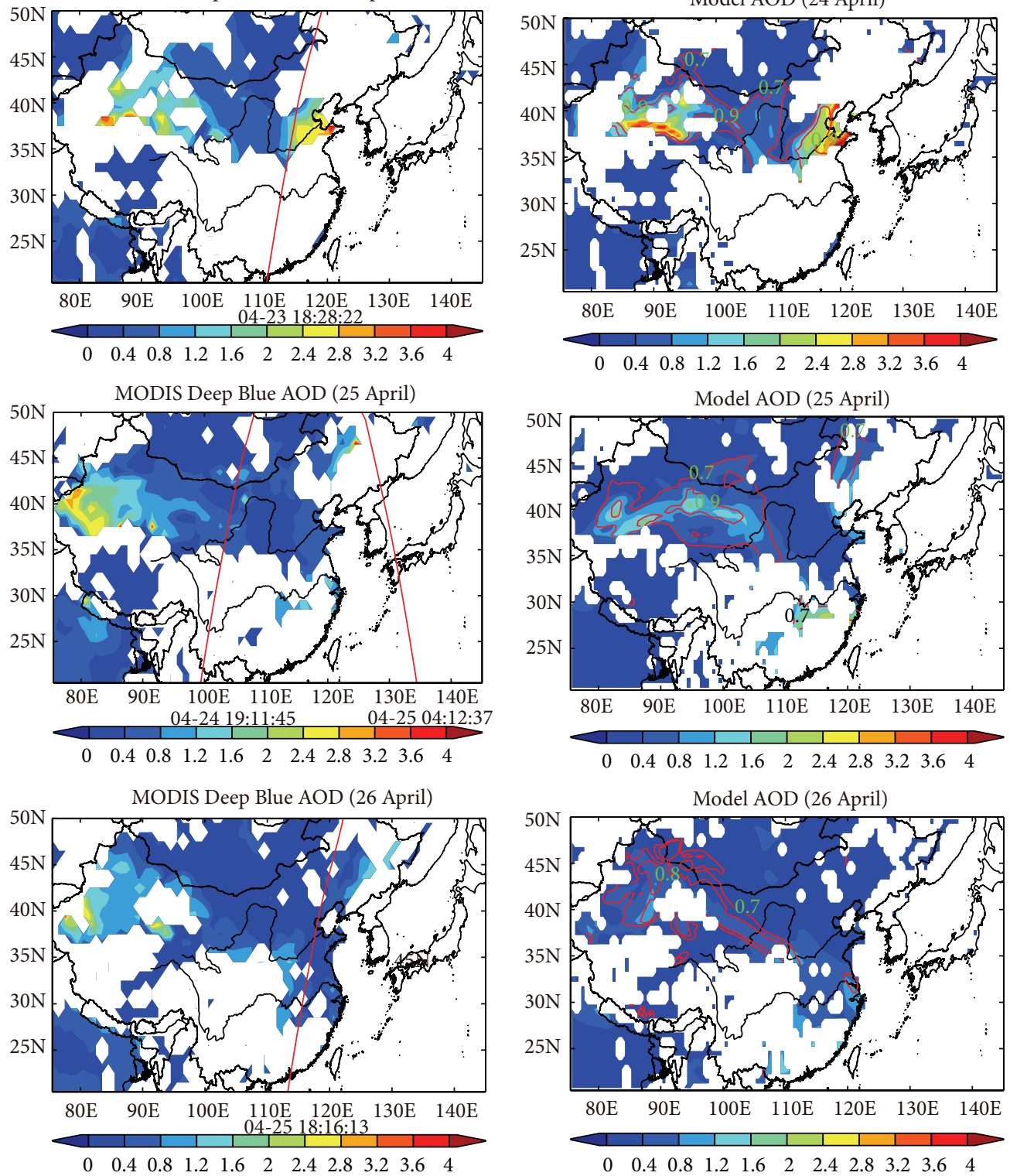

(c)

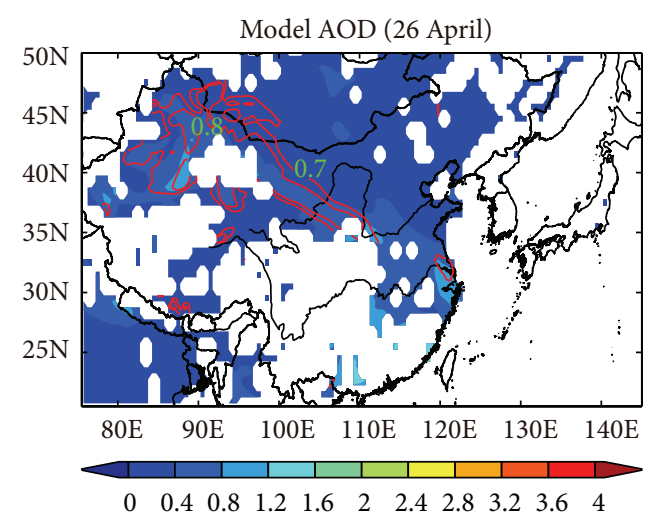

(d)

FIgure 3: AOD from MODIS and the model at $550 \mathrm{~nm}$ during 23 to 26 April 2009 (LST): (a) MODIS Aqua "Land and Ocean" AOD product; (b) modeled AOD sampling according to (a); (c) MODIS Aqua "Deep Blue Land only" AOD product; (d) modeled AOD sampling according to (c). CALIPSO orbit paths (red lines) and path times (at the bottom of each path, UTC time, MM-DD HH:MM:SS) are presented in MODIS AOD figures ((a), (c)). Fractional contributions of dust to total AOD are indicated in modeled AOD figures ((b), (d), red contour lines with light blue numbers). 
4.3. Comparison with CALIOP Products. The orbit of the CALIPSO satellite that approximately crossed the body of the dust storm was selected for each day (see Figures 3(a) and $3(c)$ ) to depict the vertical evolution of the dust transport. Figure 4 presents profiles of aerosol subtype information (left column) and aerosol extinction coefficient at $532 \mathrm{~nm}$ from CALIOP measurements (middle column) and simulated vertical distributions of aerosol extinction coefficient at $550 \mathrm{~nm}$ (right column). As this study mainly focuses on dust aerosol, fractional contributions of dust to total aerosol extinction estimated by the model were also displayed. The main body of a dust plume was assumed to have the fractional value of greater than 0.7 in this study.

On 23 April when the dust storm occurred in the Gobi desert, the CALIPSO satellite flew across this dust source region. Along this orbit (Figure 4(a)), a pure dust plume was detected by CALIOP in the range of about $37^{\circ} \mathrm{N}$ to $45^{\circ} \mathrm{N}$ and between altitudes of about $1 \mathrm{~km}$ to $8 \mathrm{~km}$ (left column in Figure 4(a)). The corresponding distribution of measured aerosol extinction coefficient (middle column in Figure 4(a)) showed the largest values $\left(\geq 1.0 \mathrm{~km}^{-1}\right)$ locating around $40^{\circ} \mathrm{N}$ and relatively large values $\left(0.3-1.0 \mathrm{~km}^{-1}\right)$ locating between $40^{\circ} \mathrm{N}$ and $45^{\circ} \mathrm{N}$ at lower altitudes $(1-3 \mathrm{~km})$, indicating most dust aerosol distributed below about $3 \mathrm{~km}$. Right column in Figure 4(a) was the vertical distribution of simulated aerosol extinction coefficients and fractional contributions of dust to total aerosol extinction coefficient greater than 0.7. It is found that the model reasonably reflected the span $\left(37^{\circ}-\right.$ $45^{\circ} \mathrm{N}$ ) and the elevation (from surface to about $7 \mathrm{~km}$ ) of the dust plume, reproducing the largest aerosol extinction coefficient center at around $40^{\circ} \mathrm{N}$ within $3 \mathrm{~km}$, but the model seemed to underestimate measurements. It should be noted that the CALIOP retrieved aerosol extinction coefficients $\geq 1.0 \mathrm{~km}^{-1}$ (in red color in the middle column of Figure 4) are of higher uncertainties that it can be used to reflect dust plume qualitatively rather than quantitatively.

On the midnight of 24 April (UTC time, the afternoon of 23 April), the CALIPSO satellite crossed the North China Plain which was affected by the main body of the dust storm (see Figure 3). Aerosols classified as pure dust by CALIOP located between $35^{\circ} \mathrm{N}$ and $40^{\circ} \mathrm{N}$ and stretched from surface to about $10 \mathrm{~km}$ (left column in Figure 4(b)). Measured aerosol extinction coefficients $\geq 1.0 \mathrm{~km}^{-1}$ were found to stretch from surface to about $3 \mathrm{~km}$ within the latitude ban of $35^{\circ}-40^{\circ} \mathrm{N}$, but the values decreased sharply to about $0.1 \mathrm{~km}^{-1}$ above $4 \mathrm{~km}$, indicating that most dust aerosols were restricted within this altitude (middle column in Figure 4(b)). The model reasonably simulated the location $\left(35^{\circ} \mathrm{N}\right.$ to about $\left.42^{\circ} \mathrm{N}\right)$ and the vertical extension (from surface to $8 \mathrm{~km}$ ) of the dust plume but overestimated the total aerosol extinction coefficient above $4 \mathrm{~km}$ (right column in Figure 4(b)).

The presented CALIOP aerosol profiles on the midnight of 25 April (Figure 4(c)) belong to an orbit path crossing the tail-end of the dust storm (Figure 3). As detected by CALIOP, dust aerosol located between $35^{\circ} \mathrm{N}$ and $40^{\circ} \mathrm{N}$ and between $1 \mathrm{~km}$ and $10 \mathrm{~km}$ (left column in Figure 4(c)), with high aerosol extinction coefficient center (about 0.4$1.0 \mathrm{~km}^{-1}$ ) appearing at the altitude of around $3 \mathrm{~km}$ (middle column in Figure 4(c)). The model simulated the location and the vertical distribution of dust aerosol reasonably well (right column in Figure 4(c)); however, although the model simulated the largest contribution of dust to total aerosol extinction coefficient at $2-3 \mathrm{~km}$ (fractional value of $\geq 0.9$ ), it underestimated the intensity of this high aerosol extinction coefficient center revealed by CALIOP.

CALIOP retrievals and simulations along another orbit path crossing the west Pacific Ocean at noon of 25 April (see Figures 3(a) and 3(c)) are shown in Figure 4(d). The main body of the dust storm was found at about $35^{\circ}-40^{\circ} \mathrm{N}$ around $2-4 \mathrm{~km}$ (left and middle columns in Figure 4(d)). The model reasonably reproduced the main features of the dust plume (right column in Figure 4(d)). Both CALIOP measurement and simulation indicated that there was dust plume transported out of the continent between latitudes of about $35^{\circ}-40^{\circ} \mathrm{N}$ at altitude of $2-4 \mathrm{~km}$ on 25 April. The analysis of MODIS and CALIOP retrievals revealed that the dust storm transported in two directions; one was a southeastward pathway from the Gobi desert to south China; the other one was an eastward pathway from source region to the west Pacific Ocean.

The CALIPSO orbit path also passed over the tail-end of the dust plume on 26 April (see Figures 3(a) and 3(c)). The detected dust plume could be divided into two major parts, namely, (1) $25^{\circ}-30^{\circ} \mathrm{N}$, below $3 \mathrm{~km}$, and (2) $30^{\circ}-35^{\circ} \mathrm{N}$, from surface to $10 \mathrm{~km}$ (left column in Figure 4(e)), with aerosol extinction coefficients of about $0.3-1.0 \mathrm{~km}^{-1}$ and about $0.1 \mathrm{~km}^{-1}$, respectively (middle column in Figure 4(e)). The corresponding simulated aerosol extinction coefficient was generally consistent with the measurement features of the dust plume, but the model seemed to underestimate the contribution of dust to aerosol extinction coefficient for the 2nd part of the plume below $3 \mathrm{~km}$ (right column in Figure 4(e)). The model also reproduced the dust plume extending vertically from surface to about $8 \mathrm{~km}$ in between $35^{\circ}$ and $45^{\circ} \mathrm{N}$ (right column), which was classified as "polluted dust" by CALIOP (left column).

The comparisons made in Section 4 demonstrated that RAQMS was able to represent the temporal, horizontal, and vertical evolution of the dust storm during 23 to 26 April, 2009 , reasonably well. This supports the reliability of model analysis of dust structure and its evolution process in the following section.

\section{Three-Dimensional Structure of the Dust Storm and Its Evolution Process}

Figure 5(a) presents the daily mean ground-level dust concentration and dust-induced AOD during the dust storm period, and Figure 5(b) shows the daily mean vertical distribution of dust concentration and dust extinction coefficient for east China (zonal average from $105^{\circ} \mathrm{E}$ to $125^{\circ} \mathrm{E}$ ). At the outbreak of the dust storm (23 April), large amount of dust aerosol was generated on the Gobi desert and the Taklamakan desert, with the maximum daily surface concentration exceeding $8 \mathrm{mg} / \mathrm{m}^{3}$ over the two source regions. Dust aerosol resulted in maximum daily mean dust-induced 

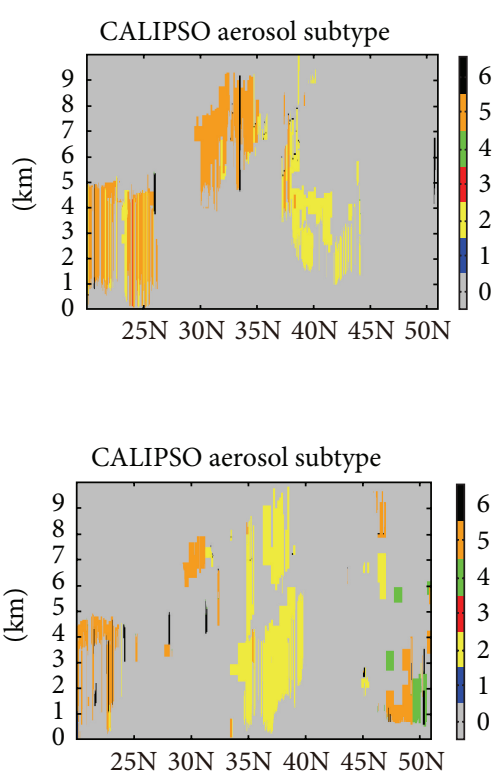

CALIPSO aerosol subtype
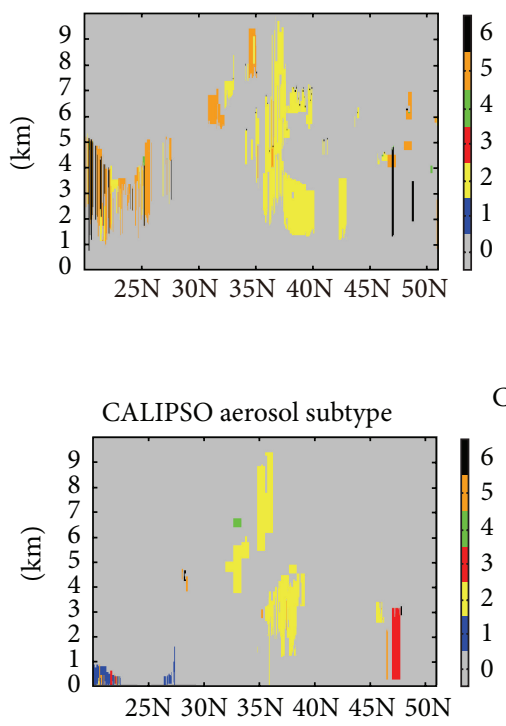

CALIPSO aerosol subtype

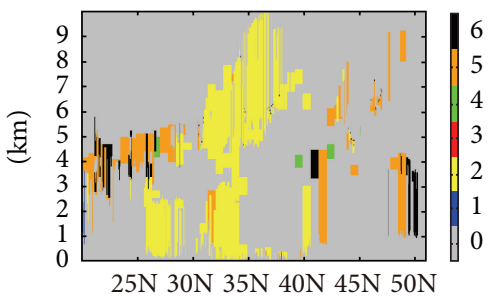



(a)

CALIPSO aerosol extinction coefficient $\left(\mathrm{km}^{-1}\right)$

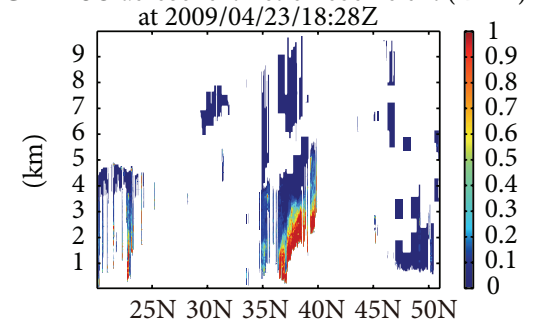

(b)

CALIPSO aerosol extinction coefficient $\left(\mathrm{km}^{-1}\right)$

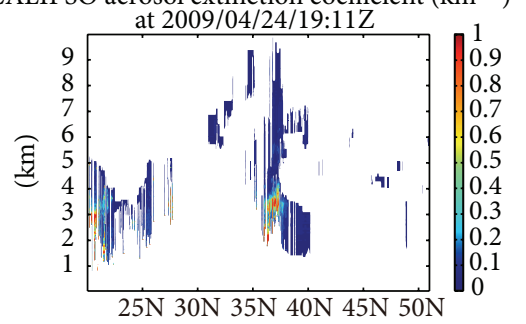

(c)

CALIPSO aerosol extinction coefficient $\left(\mathrm{km}^{-1}\right)$



(d)

CALIPSO aerosol extinction coefficient $\left(\mathrm{km}^{-1}\right)$

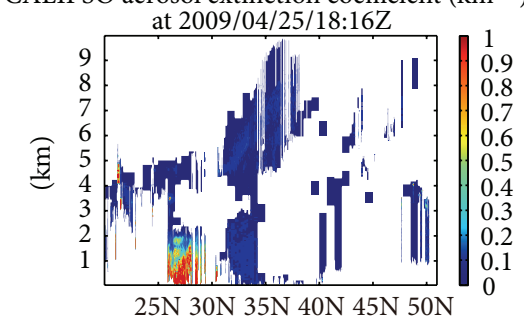

RAQMS aerosol extinction coefficient $\left(\mathrm{km}^{-1}\right)$
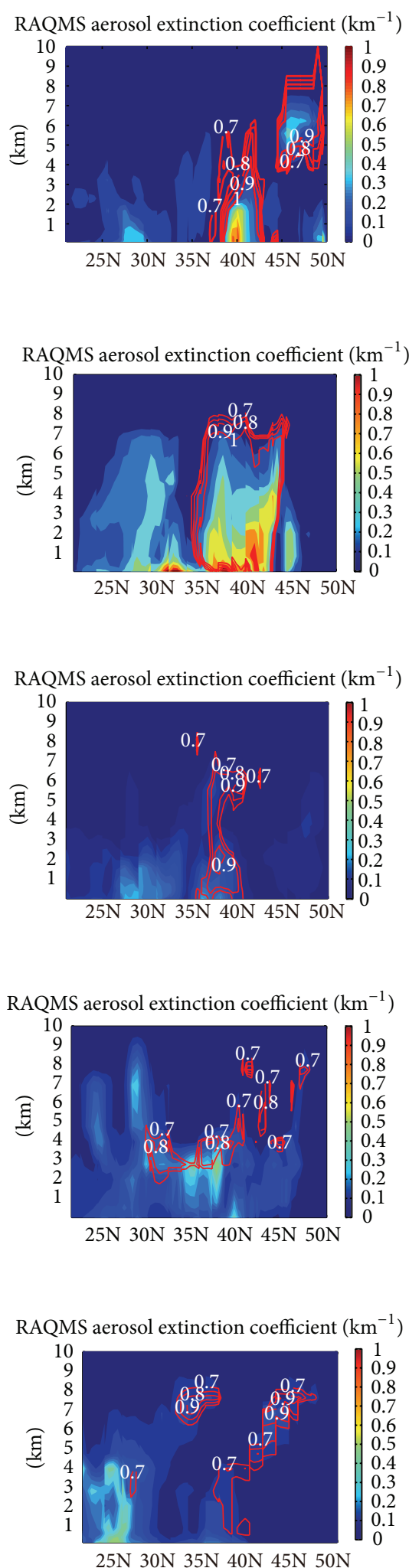

$25 \mathrm{~N} 30 \mathrm{~N} 35 \mathrm{~N} 40 \mathrm{~N} 45 \mathrm{~N} 50 \mathrm{~N}$

(e)

)



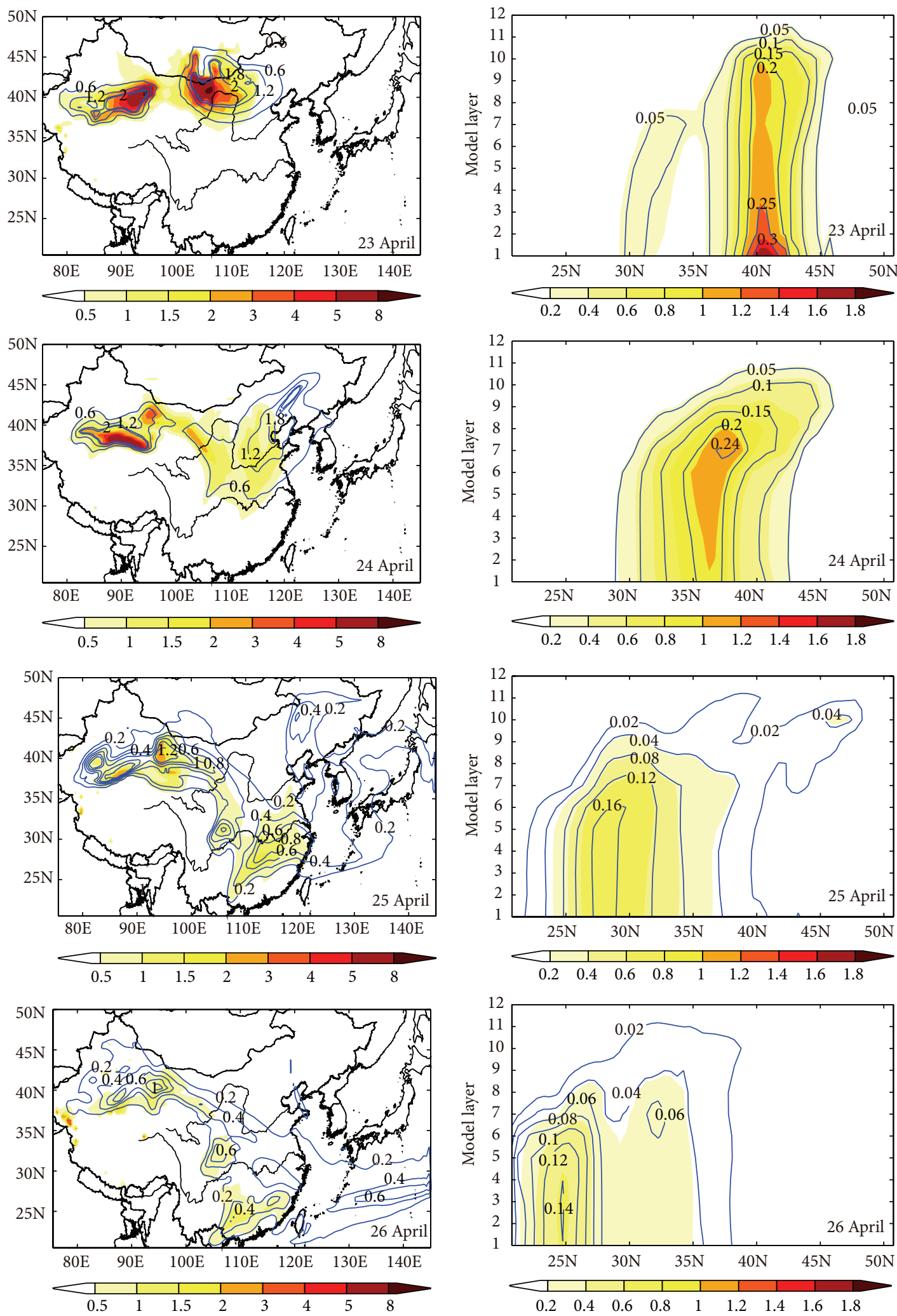

(a)



(b)

FIGURE 5: Daily mean (a) surface dust concentration $\left(\mathrm{mg} / \mathrm{m}^{3}\right)$ and dust-induced AOD (blue contours with numbers) and (b) sectional average over $105^{\circ}-125^{\circ} \mathrm{E}$ of dust concentration $\left(\mathrm{mg} / \mathrm{m}^{3}\right)$ and dust extinction coefficient $\left(\mathrm{km}^{-1}\right.$, blue contours with numbers) for the dust storm period (23-26 April) from model simulation. 
AOD of up to 2.0 over these two deserts. The vertical profile of dust concentration for east China shows that there was a dust concentration center at about $40^{\circ}-41^{\circ} \mathrm{N}$, with the largest concentration $\left(>1.4 \mathrm{mg} / \mathrm{m}^{3}\right)$ and extinction coefficient $\left(>0.3 \mathrm{~km}^{-1}\right)$ situated below about $200 \mathrm{~m}$ (the 2nd model layer). The top of the dust storm exceeded $8 \mathrm{~km}$ (11th layer), with high dust concentration $\left(\geq 1.0 \mathrm{mg} / \mathrm{m}^{3}\right)$ and large dust aerosol extinction coefficient $\left(\geq 0.2 \mathrm{~km}^{-1}\right)$ extending from surface to near $7 \mathrm{~km}$ (10th layer) due to vertical mixing.

On 24 April, the main body of the dust storm transported southeastward off the Gobi desert, resulting in daily mean surface dust concentration of about $1.0-1.5 \mathrm{mg} / \mathrm{m}^{3}$ and daily mean dust AOD of 1.2-1.8 over most areas of the North China Plain. Dust concentration and dust AOD could be in ranges of $1.0-1.5 \mathrm{mg} / \mathrm{m}^{3}$ and $0.6-1.2$ over the middle and lower reaches of the Yellow River on this day. It should be noticed that there was another large AOD center (1.2-1.8) with sharp gradient locating over northeast China where there was very low ground-level dust concentration; that is because a branch of dust was transported eastward off the Gobi desert at higher altitudes. High dust concentration of about $1.0-1.2 \mathrm{mg} / \mathrm{m}^{3}$ stretched straight from near surface to about $2 \mathrm{~km}$ (6th-7th layers) at around $36^{\circ} \mathrm{N}$. Above $2 \mathrm{~km}$, the dust concentration center shifted north to nearly $39^{\circ} \mathrm{N}$. High dust concentrations mainly appeared at higher altitudes (such as $2-4 \mathrm{~km}$ ) rather than at the surface on this day, resulting in the largest dust extinction coefficient of about $0.24 \mathrm{~km}^{-1}$ appearing at about $2.5 \mathrm{~km}$ (7th layer).

The main body of the dust storm transported to south China on 25 April, leading to ground-level dust concentration of $0.5-1.5 \mathrm{mg} / \mathrm{m}^{3}$ over south of middle and lower reaches of the Yangtze River. At the meantime, the high center of dust-induced AOD moved accordingly to south China but the value decreased to about 0.4-0.8. The high AOD center over northeast China remained there but the maximum value decreased sharply from about 1.8 to 0.4 . The top of the dust storm (dust concentration $\geq 0.2 \mathrm{mg} / \mathrm{m}^{3}$ ) lowered to about $4.5 \mathrm{~km}$ (9th layer) over east China. High dust concentration in vertical direction decreased to $0.6-0.8 \mathrm{mg} / \mathrm{m}^{3}$ between about $26^{\circ}-32^{\circ} \mathrm{N}$, with dust extinction coefficient also weakened to about $0.12-0.16 \mathrm{~km}^{-1}$. Dust concentration as well as dust extinction coefficient was higher at around $2.5 \mathrm{~km}$ (7th layer) then at the surface in between $35^{\circ}$ and $40^{\circ} \mathrm{N}$. The high dust extinction coefficient center over northeast China was found at about $6 \mathrm{~km}$ (10th layer), with the maximum value of about $0.04 \mathrm{~km}^{-1}$. Vertical distribution patterns of dust concentration and dust extinction coefficient for 24 and 25 April reveal that the transport pathway of the dust storm split into two over east China: the low altitude pathway (below $2 \mathrm{~km}$ ) was in a southeastward direction from the Gobi desert to south China while the high altitude pathway (above $2 \mathrm{~km}$ ) was in an eastward direction from source region to the west Pacific Ocean along $35^{\circ}-40^{\circ} \mathrm{N}$, consistent with comparisons between satellite measurements and simulations in Sections 4.2 and 4.3. Wind directions varied at different altitudes were the reason. On these two days, wind directions at altitudes below $2 \mathrm{~km}$ over east China were dominated by north wind, resulting in southward transport of dust aerosols; however, at altitudes above $2 \mathrm{~km}$, the westerly and northwesterly controlled east China; as a result, dust aerosols were conveyed from the Gobi desert to the west Pacific Ocean between $35^{\circ}$ and $40^{\circ} \mathrm{N}$ (figures of the wind field were not shown).

The dust storm moved further south on 26 April, with lower ground-level concentration $\left(0.5-1.0 \mathrm{mg} / \mathrm{m}^{3}\right)$ and smaller coverage. As a result, dust-induced AOD decreased to about $0.2-0.4$ over south China. The top of the dust storm also further decreased to near $2.5 \mathrm{~km}$ (7th layer). The high dust center located at around $25^{\circ} \mathrm{N}$, with daily concentration of about $0.4-0.6 \mathrm{mg} / \mathrm{m}^{3}$ and dust extinction coefficient of about $0.12-0.14 \mathrm{~km}^{-1}$. The dust storm episode was actually finished on this day.

During this dust storm period (23-26 April, 2009), the model estimated that a total of $2.24 \times 10^{4} \mathrm{Gg}$ dust particles were generated over the Gobi desert and the Taklamakan desert. About $50 \%\left(1.12 \times 10^{4} \mathrm{Gg}\right)$ of emitted dust particles were redeposited onto the ground by dry deposition process. The dry deposition amount of dust was about $5-15 \mathrm{~g} / \mathrm{m}^{2}$ over dust source regions and the amount decreased sharply to less than $0.5 \mathrm{~g} / \mathrm{m}^{2}$ over downwind areas such as south China and the West Pacific Ocean. The removal of dust due to wet scavenging process accounted for about $16 \%$ of generated dust particles. Different from dry deposition, wet scavenge mainly occurred over downwind areas such as north China, the middle and lower reaches of the Yangtze River, and the West Pacific Ocean. The amount of wet scavenged dust was estimated to be in the range of about $0.5-10 \mathrm{~g} / \mathrm{m}^{2}$ over these downwind areas. The rest $34 \%$ emitted dust was subjected to long-range transport.

\section{Conclusion}

The three-dimensional evolution of a dust storm occurring over East Asia from 23 to 26 April 2009 was investigated by using the regional model RAQMS. Major focuses of this study have been placed on model validation and analyses of dust storm evolution. A variety of observational data including in situ ground-level $\mathrm{PM}_{10}$ and inorganic aerosol observations at Mt. Tai, aerosol optical depth (AOD) retrievals from MODIS, and profile aerosol extinction coefficient and aerosol subtype information from CALIOP were used to evaluate the model performance and investigate the evolution of the dust storm. Comparing with ground-level observations at Mt. Tai, the model well reproduced the magnitude of the dust storm on 23-26 April, predicting maximum daily $\mathrm{PM}_{10}$ concentration of $\sim 1600 \mu \mathrm{g} / \mathrm{m}^{3}$, close to the observed daily $\mathrm{PM}_{10}$ concentration peak of $\sim 1400 \mu \mathrm{g} / \mathrm{m}^{3}$. During the whole observation period (27 March-26 April), the mean $\mathrm{PM}_{10}$ concentrations at Mt. Tai for observation and simulation were $201 \mu \mathrm{g} / \mathrm{m}^{3}$ and $200 \mu \mathrm{g} / \mathrm{m}^{3}$, respectively, with correlation coefficient of 0.92 . The model also reasonably reproduced concentration levels of inorganic aerosol components at Mt. Tai. Comparison with MODIS retrievals demonstrated that the model performed well on reproducing the magnitude and the distribution pattern of AOD during the dust storm period, and comparison with CALIOP measurements showed that the model was able to reasonably simulate the vertical distribution of aerosol 
extinction coefficient. Model validation indicated that the model was capable of reproducing the three-dimensional structure and the evolution of the dust storm, capturing major features of the dust storm reasonably well.

The dust storm was originated from the Gobi desert. During the early days of the dust storm, the ground-level daily dust concentration could be higher than $8 \mathrm{mg} / \mathrm{m}^{3}$ over dust source regions and $1.0-1.5 \mathrm{mg} / \mathrm{m}^{3}$ over the North China Plain, resulting in daily mean dust-induced AOD to be as high as 2.0 over desert areas and in a range of 1.2-1.8 over vast areas of the North China Plain. As a result, dust-induced AOD could account for $98 \%$ and up to $90 \%$ of total AOD over desert areas and parts of north China, respectively, during the first two days of the dust storm. The top of the dust storm could reach as high as about $8 \mathrm{~km}$ at the beginning, with high dust concentration $\left(\geq 1.0 \mathrm{mg} / \mathrm{m}^{3}\right)$ and large dust aerosol extinction coefficient $\left(\geq 0.2 \mathrm{~km}^{-1}\right)$ extending from surface to about $7 \mathrm{~km}$. Vertical distribution of dust concentration also showed that the transport pathway of this dust storm was split into two, dust aerosols at lower altitude (below $2 \mathrm{~km}$ ) were transported southeastward from the Gobi desert to south China while aerosols at higher altitude (above $2 \mathrm{~km}$ ) were transported eastward out of China along $35^{\circ}-40^{\circ} \mathrm{N}$. During last days of the dust storm, although the ground-level dust concentration, dust-induced AOD, and the altitude of dust top over south China were all decreased obviously, the contribution of dust to total AOD was still approaching $40 \%$ over these areas, implying the important implications of the dust storm on radiative forcing in southern parts of China. During this dust storm period (23-26 April, 2009), a total of $2.24 \times 10^{4} \mathrm{Gg}$ dust aerosols were estimated to be generated over East Asia, about $50 \%$ and $16 \%$ of them were removed by dry deposition and wet scavenging processes, respectively, and $34 \%$ of them were subjected to long-range transport.

\section{Conflict of Interests}

The authors declare that there is no conflict of interests regarding the publication of this paper.

\section{Acknowledgments}

This study was supported by the National 973 Project of China (2014CB953703) and the National Natural Science Foundation of China (Grant no. 41375151). The authors would like to thank Professor Gehui Wang for providing observation data at Mt. Tai and the MODIS science data support team for maintaining and providing MODIS AOD retrievals. The CALIOP data were obtained from the NASA Langley Research Center Atmospheric Sciences Data Center.

\section{References}

[1] I. N. Sokolik and O. B. Toon, "Direct radiative forcing by anthropogenic airborne mineral aerosols," Nature, vol. 381, no. 6584, pp. 681-683, 1996.

[2] I. Tegen, S. P. Harrison, K. Kohfeld, I. C. Prentice, M. Coe, and M. Heimann, "Impact of vegetation and preferential source areas on global dust aerosol: Results from a model study," Journal of Geophysical Research D: Atmospheres, vol. 107, no. 21, article 4576, 2002.

[3] Y. Shao and C. H. Dong, "A review on East Asian dust storm climate, modelling and monitoring," Global and Planetary Change, vol. 52, no. 1-4, pp. 1-22, 2006.

[4] X. Y. Zhang, S. L. Gong, Z. X. Shen et al., "Characterization of soil dust aerosol in China and its transport and distribution during 2001 ACE-Asia: 1. Network observations," Journal of Geophysical Research D: Atmospheres, vol.108, no. 9, article 4261, 2003.

[5] S. L. Gong, X. Y. Zhang, T. L. Zhao, I. G. McKendry, D. A. Jaffe, and N. M. Lu, "Characterization of soil dust aerosol in China and its transport and distribution during 2001 ACEAsia: 2. Model simulation and validation," Journal of Geophysical Research D: Atmospheres, vol. 108, no. 9, 2003.

[6] Z. Han, H. Ueda, K. Matsuda et al., "Model study on particle size segregation and deposition during Asian dust events in March 2002," Journal of Geophysical Research D: Atmospheres, vol. 109, no. 19, article 19205, 2004.

[7] J. Huang, Q. Fu, J. Su et al., “Taklimakan dust aerosol radiative heating derived from CALIPSO observations using the FuLiou radiation model with CERES constraints," Atmospheric Chemistry and Physics, vol. 9, no. 12, pp. 4011-4021, 2009.

[8] K. M. Lau, M. K. Kim, and K. M. Kim, "Asian summer monsoon anomalies induced by aerosol direct forcing: the role of the Tibetan Plateau," Climate Dynamics, vol. 26, no. 7-8, pp. 855864, 2006.

[9] R. B. Husar, D. M. Tratt, B. A. Schichtel et al., "Asian dust events of April 1998," Journal of Geophysical Research D: Atmospheres, vol. 106, no. 16, pp. 18317-18330, 2001.

[10] G. Wang, J. Li, C. Cheng et al., "Observation of atmospheric aerosols at Mt. Hua and Mt. Tai in central and East China during spring 2009-part 1: EC, OC and inorganic ions," Atmospheric Chemistry and Physics, vol. 11, no. 9, pp. 4221-4235, 2011.

[11] N. Sugimoto, A. Shimizu, I. Matsui et al., "Study of asian dust phenomena in 2001-2003 using a network of continuously operated polarization lidars," Water, Air, and Soil Pollution: Focus, vol. 5, no. 3-6, pp. 145-157, 2005.

[12] D. M. Winker, M. A. Vaughan, A. Omar et al., "Overview of the CALIPSO mission and CALIOP data processing algorithms," Journal of Atmospheric and Oceanic Technology, vol. 26, no. 11, pp. 2310-2323, 2009.

[13] I. Uno, K. Yumimoto, A. Shimizu et al., "3D structure of Asian dust transport revealed by CALIPSO lidar and a 4DVAR dust model," Geophysical Research Letters, vol. 35, no. 6, Article ID L06803, 2008.

[14] K. Eguchi, I. Uno, K. Yumimoto et al., "Trans-pacific dust transport: Integrated analysis of NASA/CALIPSO and a global aerosol transport model," Atmospheric Chemistry and Physics, vol. 9, no. 9, pp. 3137-3145, 2009.

[15] Y. Shao, Y. Yang, J. Wang et al., "Northeast Asian dust storms: Real-time numerical prediction and validation," Journal of Geophysical Research D: Atmospheres, vol. 108, no. 22, Article ID 4691, 2003.

[16] Z. Han, J. Li, W. Guo, Z. Xiong, and W. Zhang, "A study of dust radiative feedback on dust cycle and meteorology over East Asia by a coupled regional climate-chemistry-aerosol model," Atmospheric Environment, vol. 68, pp. 54-63, 2013.

[17] J. Li, Z. W. Han, and R. J. Zhang, "Model study of atmospheric particulates during dust storm period in March 2010 over East 
Asia," Atmospheric Environment, vol. 45, no. 24, pp. 3954-3964, 2011.

[18] W. P. L. Carter, "Documentation of the SAPRC-99 chemical mechanism for VOC reactivity assessment," Final Report Contract no. 92-329 and 95-308, California Air Resources Board, 2000.

[19] C. Fountoukis and A. Nenes, "ISORROPIAII: a computationally efficient thermodynamic equilibrium model for $\mathrm{K}^{+}-\mathrm{Ca}^{2+}-$ $\mathrm{Mg}^{2+}-\mathrm{NH}_{4}{ }^{+}-\mathrm{Na}^{+}-\mathrm{SO}_{4}{ }^{2-}-\mathrm{NO}_{3}{ }^{-}-\mathrm{CI}^{-}-\mathrm{H}_{2} \mathrm{O}$ aerosols," Atmospheric Chemistry and Physics, vol. 7, no. 17, pp. 4639-4659, 2007.

[20] D. A. Lack, X. X. Tie, N. D. Bofinger, A. N. Wiegand, and S. Madronich, "Seasonal variability of secondary organic aerosol: a global modeling study," Journal of Geophysical Research D: Atmospheres, vol. 109, no. 3, Article ID D03203, 2004.

[21] J. W. Li and Z. W. Han, "A modeling study of the impact of heterogeneous reactions on mineral aerosol surfaces on tropospheric chemistry over East Asia," Particuology, vol. 8, no. 5, pp. 433-441, 2010.

[22] J. L. Walmsley and M. L. Wesely, "Modification of coded parametrizations of surface resistances to gaseous dry deposition," Atmospheric Environment, vol. 30, no. 7, pp. 1181-1188, 1996.

[23] C. J. Walcek, R. A. Brost, J. S. Chang, and M. L. Wesely, " $\mathrm{SO}_{2}$, sulfate and $\mathrm{HNO}_{3}$ deposition velocities computed using regional landuse and meteorological data," Atmospheric Environment, vol. 20, no. 5, pp. 949-964, 1986.

[24] J. S. Chang, R. A. Brost, I. S. A. Isaksen et al., "A threedimensional Eulerian acid deposition model: physical concepts and formulation," Journal of Geophysical Research, vol. 92, no. 12, pp. 14681-14700, 1987.

[25] M. D. Petters and S. M. Kreidenweis, "A single parameter representation of hygroscopic growth and cloud condensation nucleus activity," Atmospheric Chemistry and Physics, vol. 7, no. 8, pp. 1961-1971, 2007.

[26] X. Han, M. Zhang, Z. Han, J. Xin, and X. Liu, "Simulation of aerosol direct radiative forcing with RAMS-CMAQ in East Asia," Atmospheric Environment, vol. 45, no. 36, pp. 6576-6592, 2011.

[27] Z. Han, T. Sakurai, H. Ueda et al., "MICS-Asia II: model intercomparison and evaluation of ozone and relevant species," Atmospheric Environment, vol. 42, no. 15, pp. 3491-3509, 2008.

[28] Q. Zhang, D. G. Streets, G. R. Carmichael et al., "Asian emissions in 2006 for the NASA INTEX-B mission," Atmospheric Chemistry and Physics, vol. 9, no. 14, pp. 5131-5153, 2009.

[29] G. R. van der Werf, J. T. Randerson, L. Giglio et al., "Global fire emissions and the contribution of deforestation, savanna, forest, agricultural, and peat fires (1997-2009)," Atmospheric Chemistry and Physics, vol. 10, no. 23, pp. 11707-11735, 2010.

[30] Y. Li, J. An, M. Min, W. Zhang, F. Wang, and P. Xie, "Impacts of HONO sources on the air quality in Beijing, Tianjin and Hebei Province of China," Atmospheric Environment, vol. 45, no. 27, pp. 4735-4744, 2011.

[31] H. Hayami, T. Sakurai, Z. Han et al., "MICS-Asia II: model intercomparison and evaluation of particulate sulfate, nitrate and ammonium," Atmospheric Environment, vol. 42, no. 15, pp. $3510-3527,2008$. 

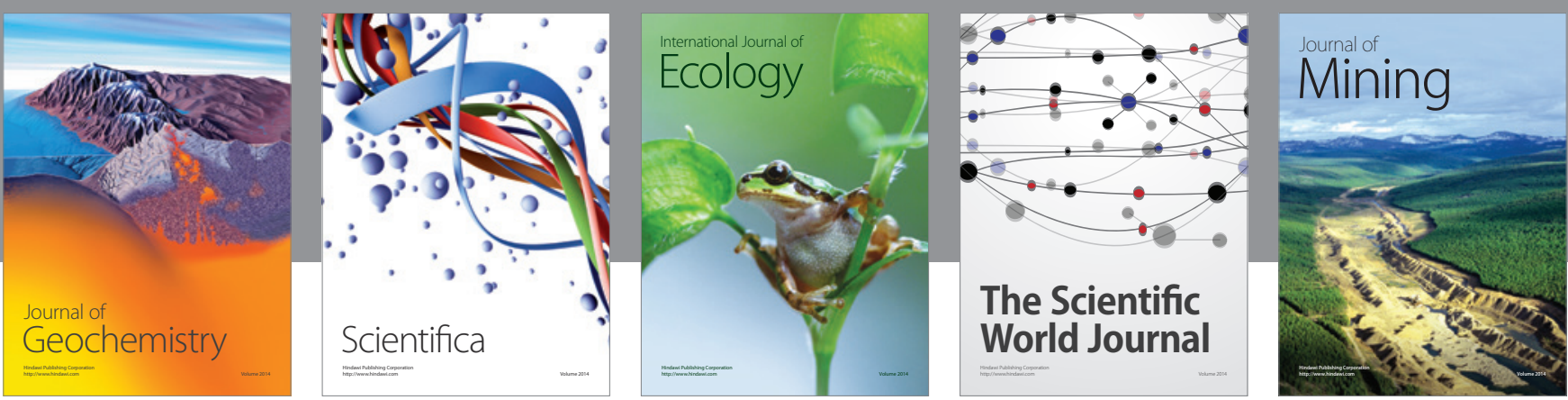

The Scientific World Journal
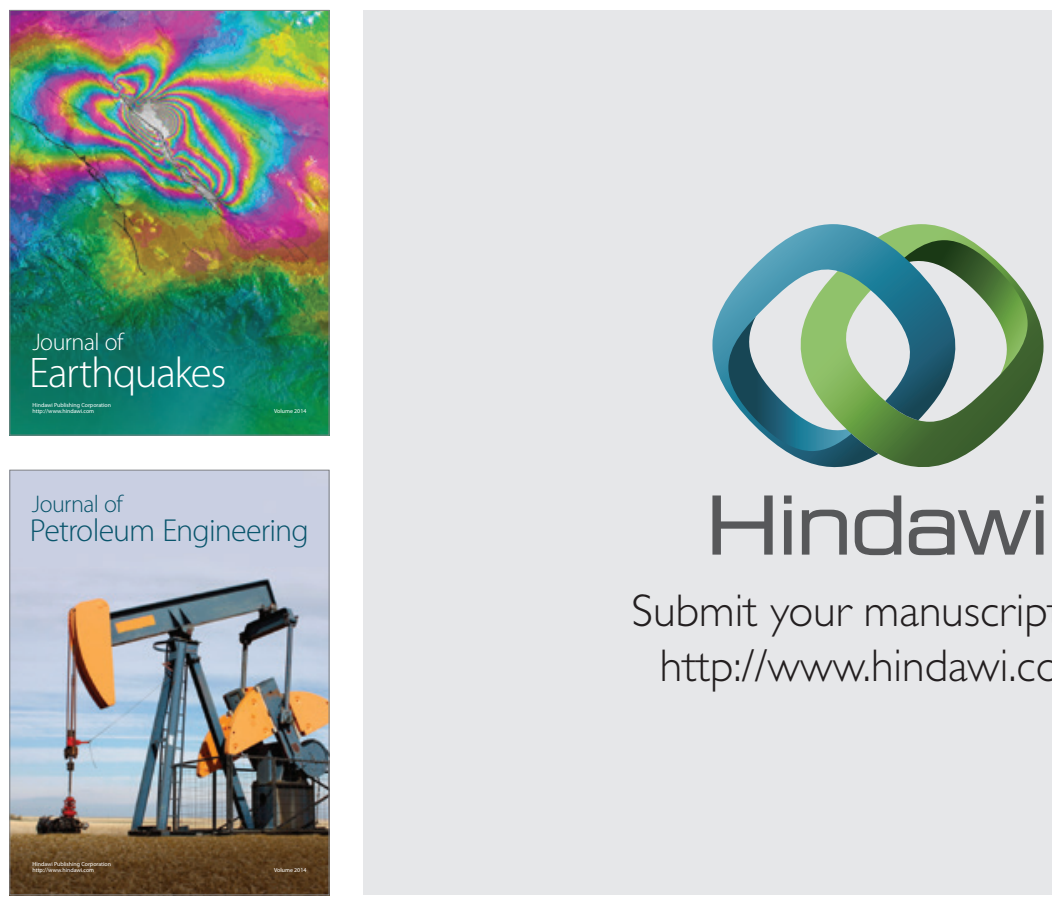

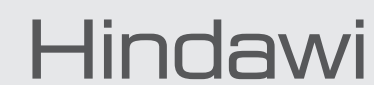

Submit your manuscripts at

http://www.hindawi.com
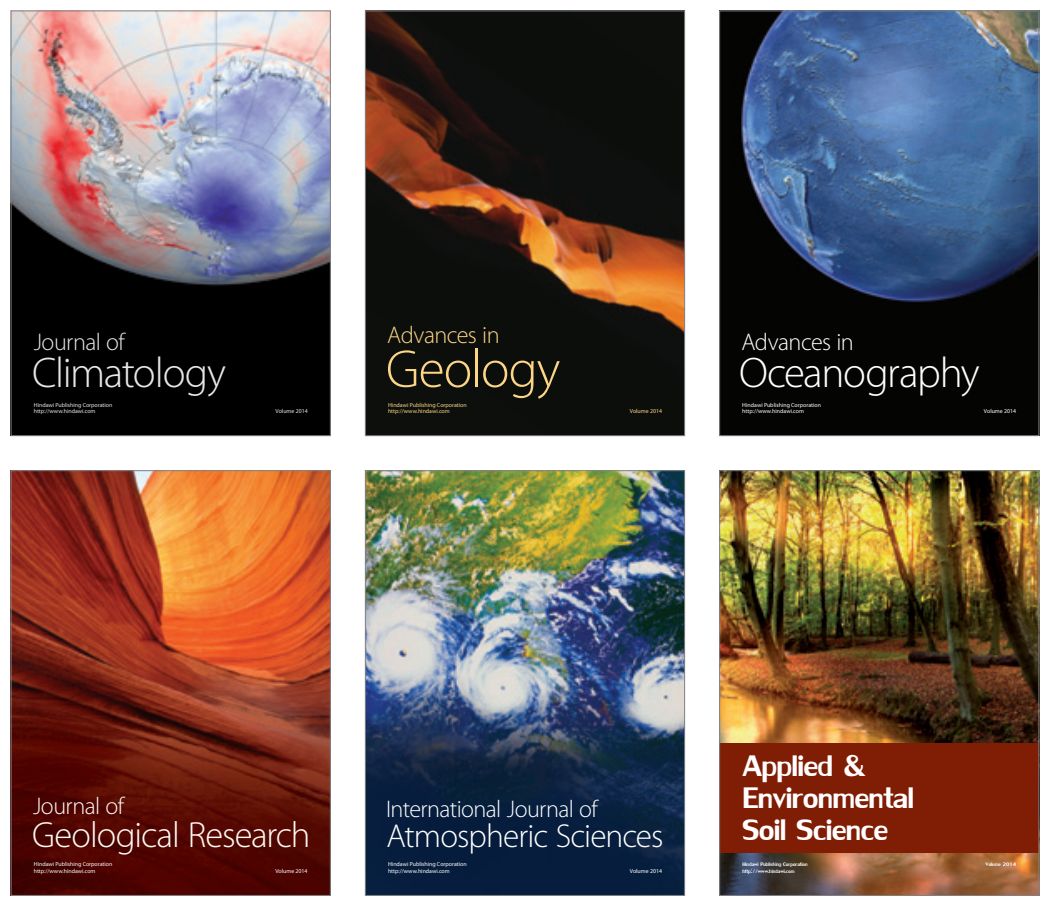
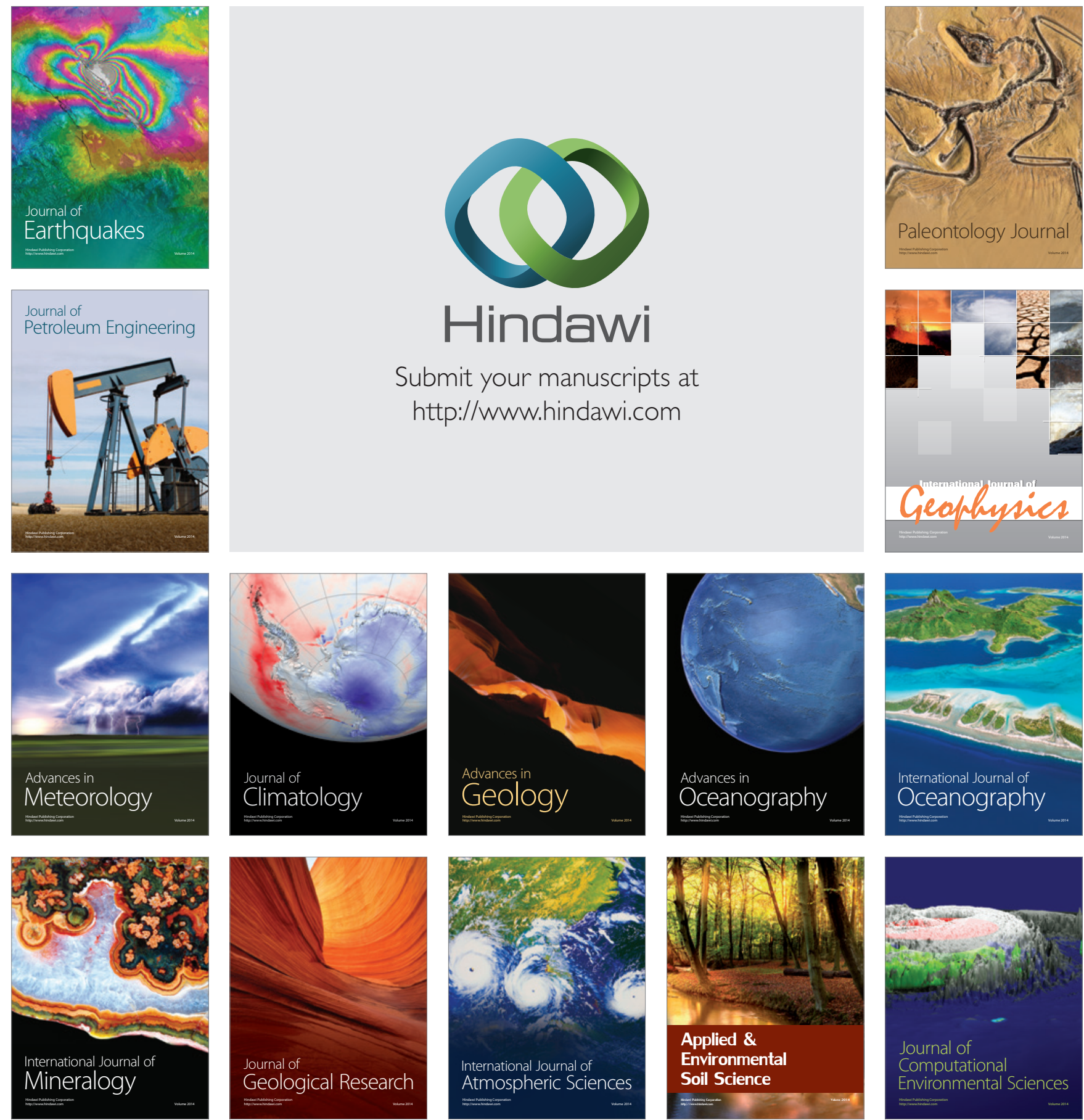